\title{
Green-Solvent-Processed Conjugated Polymers for Organic Solar Cells: The Impact of Oligoethylene Glycol Side Chains
}

\author{
Zheng Chen, ${ }^{* \dagger, \dagger}$ Liang Yan, ${ }^{\dagger}$ Jeromy James Rech, ${ }^{\dagger}$ Jun Hu, ${ }^{\dagger}$ Qianqian Zhang, ${ }^{\dagger}$ and Wei You* ${ }^{*}{ }^{\dagger}$ \\ ${ }^{\dagger}$ Department of Chemistry, University of North Carolina at Chapel Hill, Chapel Hill, North Carolina 27599-3290, United States \\ ${ }^{\ddagger}$ Key Laboratory of High-Performance Plastics (Jilin University), Ministry of Education, National \& Local Joint Engineering \\ Laboratory for Synthesis Technology of High-Performance Polymer, College of Chemistry, Jilin University, Xiuzheng Road 1788, \\ Changchun 130012, P.R. China
}
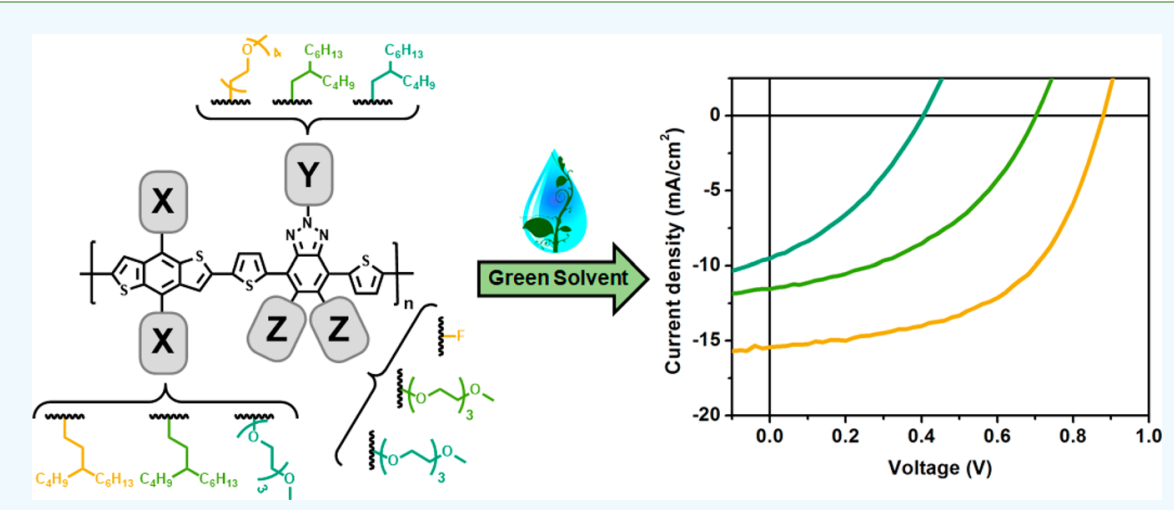

ABSTRACT: Organic photovoltaics (OPVs) possess the advantageous trait of solution processability, yet OPV blends typically use hazardous chlorinated solvents for processing. In order to realize the full advantages of OPVs, as well as growing to an industrial scale, the use of environmentally friendly solvents for processing OPVs needs to be pursued. In this study, we utilized the well-studied polymer PBnDT-FTAZ system as the model conjugated polymer, and synthesized a series of structurally similar conjugated polymers with oligo(ethylene glycol) (OEG) side-chains, aiming to understand the structural requirements to convert conventional conjugated polymers into green-processable alternatives. We elucidated the impact of these OEG chains on the properties of modified polymers when compared with the original PBnDT-FTAZ, including solubility and optoelectronic properties. Finally, aiming to understand the impact of changing side chains to the device performance, we fabricated solar cells with a nonfullerene acceptor (IT-M), achieving decent device efficiencies (over 7\%). Additionally, using renewable and green solvent, 2-methyltetrahydrofuran (2-MeTHF), we were able to achieve device efficiencies of over $2 \%$.

KEYWORDS: organic solar cells, green solvent process, oligoethylene glycol (OEG), 2-methyltetrahydrofuran (2-MeTHF), methyl-modified nonfullerene acceptor (IT-M)

\section{INTRODUCTION}

Organic photovoltaics (OPVs) have entered a new stage of rapid development, largely due to the emergence of high performance blends containing nonfullerene acceptors (NFAs). ${ }^{1-3}$ The record high power conversion efficiency (PCE) of small area single junction devices in research laboratories has been boosted up to $15.7 \%{ }^{4}$ furthermore, tandem (i.e., multijunction) devices have recently reached an unprecedented efficiency value of $17.3 \% .^{5}$ These impressive accomplishments bode well for the future commercial production; however, there are still significant issues that must be addressed. One of the unique traits of polymer based OPV is solution processability, which can significantly lower the production cost of solar cells; yet, the prevailing solvents used for processing the active layer-typically a bulk heterojunction $(\mathrm{BHJ})$ blend of conjugated polymers as the donor and organic small molecule as the acceptor-are chlorinated solvents, such as chloroform (CF), chlorobenzene (CB), dichlorobenzene (DCB), and trichlorobenzene (TCB). All of these solvents, unfortunately, are hazardous and harmful to health and environments. ${ }^{4-6}$ The impact would be exponential if polymer-based OPVs were manufactured on a commercial scale. Thus, seeking environmentally benign solvents, in particular, green solvents, ${ }^{7}$ has become increasingly important. $^{6}$

The first important step toward green-solvent-based processing is the transitioning to halogen-free solvents; there has been significant progress in this regard, with efficiency numbers breaching $12 \%$ in some cases. ${ }^{6,8-13}$ For many of these studies, toluene has been the popular choice of solvent. For

Received: January 17, 2019

Accepted: March 8, 2019

Published: March 8, 2019 
Scheme 1. Design and Structure of the Six Polymers in This Work: PBnDT-FTAZ (P1), PBnDT-FTAZ ${ }_{\text {NO }}$ (P2), PBnDT-

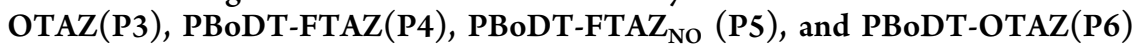

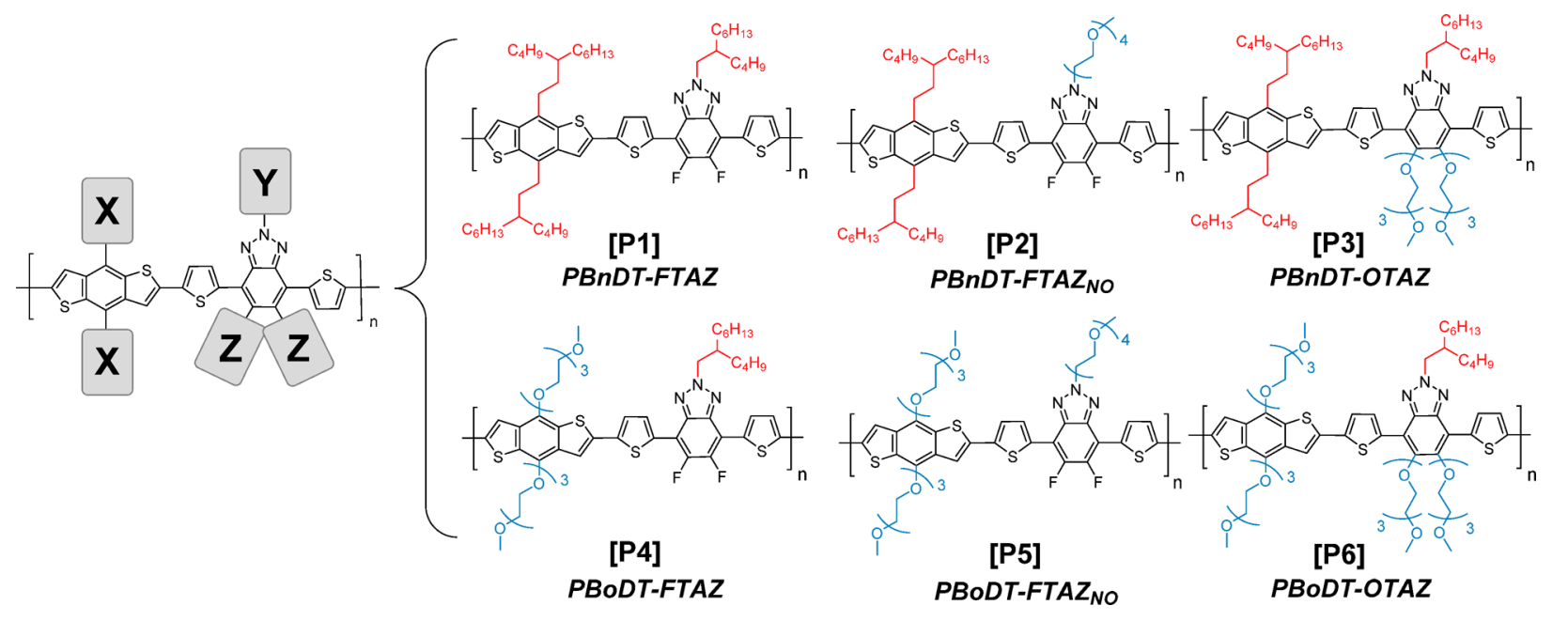

example, Ye et al. applied toluene to process FTAZ:IT-M and achieved more than $12 \%$ efficiency in early $2018 .^{9}$ Shortly after, Maojie Zhang's group also reported a high-performance polymer solar cells with $13.1 \%$ efficiency via toluene processing. 8 Another similar solvent, xylene, has also been used and demonstrated the ability to afford high performance blends. For example, Jianhui Hou's group achieved an efficiency number (13.1\%) with PBTA-TF:IT-M as the active layer and $o$-xylene/1-phenylnaphthalene as the solvent system. ${ }^{13}$ A third solvent that has also yielded success is tetrahydrofuran (THF); for example, Jianhui Hou's group reported an efficiency of $11.7 \%$ by blade-coating the active layer with a mixed solvent system of THF/isopropyl alcohol. ${ }^{13}$ The same group also accomplished an outstanding PCE of $12.10 \%$ with the THF-processed PBDB-BzT:IT-M based device. ${ }^{14}$ Ideally, green solvents would be derived from renewable sources rather than from petroleum industry. In this regard, 2-methyltetrahydrofuran (2-MeTHF), derived from renewable sources such as corncobs and bagasse, ${ }^{15}$ is a green and ecologically friendly alternative to THF. Indeed, a few research group recently reported efficiency numbers over 9\% with OPV devices with active layer processed with 2MeTHF. ${ }^{16-20}$ Ultimately, the "greenest" solvents would be simple alcohols (such as methanol and ethanol) and water, which is the most environmentally favorable.

Generally, the solubility of conjugated polymers in solvents is primarily determined by their side chains. While the typical branched alkylated side chains allow the conjugated polymers to dissolve in both halogenated and nonhalogenated solvents (such as toluene or THF), different side chains are required to render a conjugated polymer soluble in greener solvents (such as simple alcohols and water).,21-24 There are two main techniques to impart solubility of conjugated polymers in green solvents: adding oligo(ethylene glycol) side chains or adding side chains containing an ionic group. Nonionic, ethyleneglycol based side chains are preferably used to impart the solubility in green solvents, because ionic groups (together with the associated counterions) often traps charge carriers in solar cells. ${ }^{25}$ In addition, a conjugated polymer having ethylene-glycol based side chains could enjoy a higher dielectric constant, ${ }^{26-31}$ which could be beneficial for exciton splitting. In addition, since conjugated polymers are typically used as the donor in a $\mathrm{BHJ}$ blend, the acceptor (fullerenes or NFAs) would also need to be similarly engineered to render their solubility in green solvents. For example, very recently, using oligo(ethylene glycol) (OEG) as the side chains, Han Young Woo's group developed an ethanol-soluble donor-type polymer, PPDT2FBT-A, and a water-soluble acceptor, $\mathrm{PC}_{61} \mathrm{BMO}_{12}$, for green solvent processed solar cells. ${ }^{22,23,32} \mathrm{By}$ using a mixed solvent system (ethanol and water) as the processing solvent, the authors were able to achieve an efficiency value of $0.75 \%{ }^{22}$ which was later improved to $2.05 \%$. $^{32}$

These published works highlight that it is not straightforward, and is in fact very challenging, to re-engineer a $\mathrm{BHJ}$ blend previously showing high device efficiency with chlorinated solvents, to accommodate the green-solventbased processing and still accomplish high device efficiency. Open questions include: (1) How to molecularly engineer the structure of conjugated polymers to render the green solvent solubility while largely maintaining the desirable optoelectronic properties of such conjugated polymers for solar cells? More specifically, if OEG is the choice of side chains, how would the number, length, and position of these ethylene-glycol (EG)based side chains affect the solubility and optoelectronic properties of the resulting conjugated polymers? (2) How such modified conjugated polymers would impact the characteristics of their devices (i.e., efficiency, morphology, etc.) when processed with green solvents? (3) What factors would affect the efficiency of such modified polymers based solar cells, optoelectronics, morphology, or both? Additionally, can these factors be controlled to achieve similar performance to the conventional OPV blends processed with hazardous solvents?

As our initial attempt to answer these questions, we took the well-studied conjugated polymer, PBnDT-FTAZ (herein referred as FTAZ), ${ }^{33}$ which has demonstrated over $12 \%$ device efficiency in a toluene-processed $\mathrm{BHJ}$ device, ${ }^{9}$ as the model conjugated polymer in this study. We systematically replaced the branched alkyl chains in the original FTAZ polymer with OEG side chains (Scheme 1), and investigated the impact of these OEG side chains on the properties of modified FTAZ, including solubility and optoelectronic properties. Furthermore, we fabricated $\mathrm{BHJ}$ blends with selected polymers and a nonfullerene acceptor (IT-M), 
Scheme 2. Synthetic Routes of Key Building Blocks: FTAZ ${ }_{\mathrm{NO}}$, BoDT, OTAZ, TEG-I, and an Exemplary Polymer Synthesis, PBoDT-OTAZ (P6)

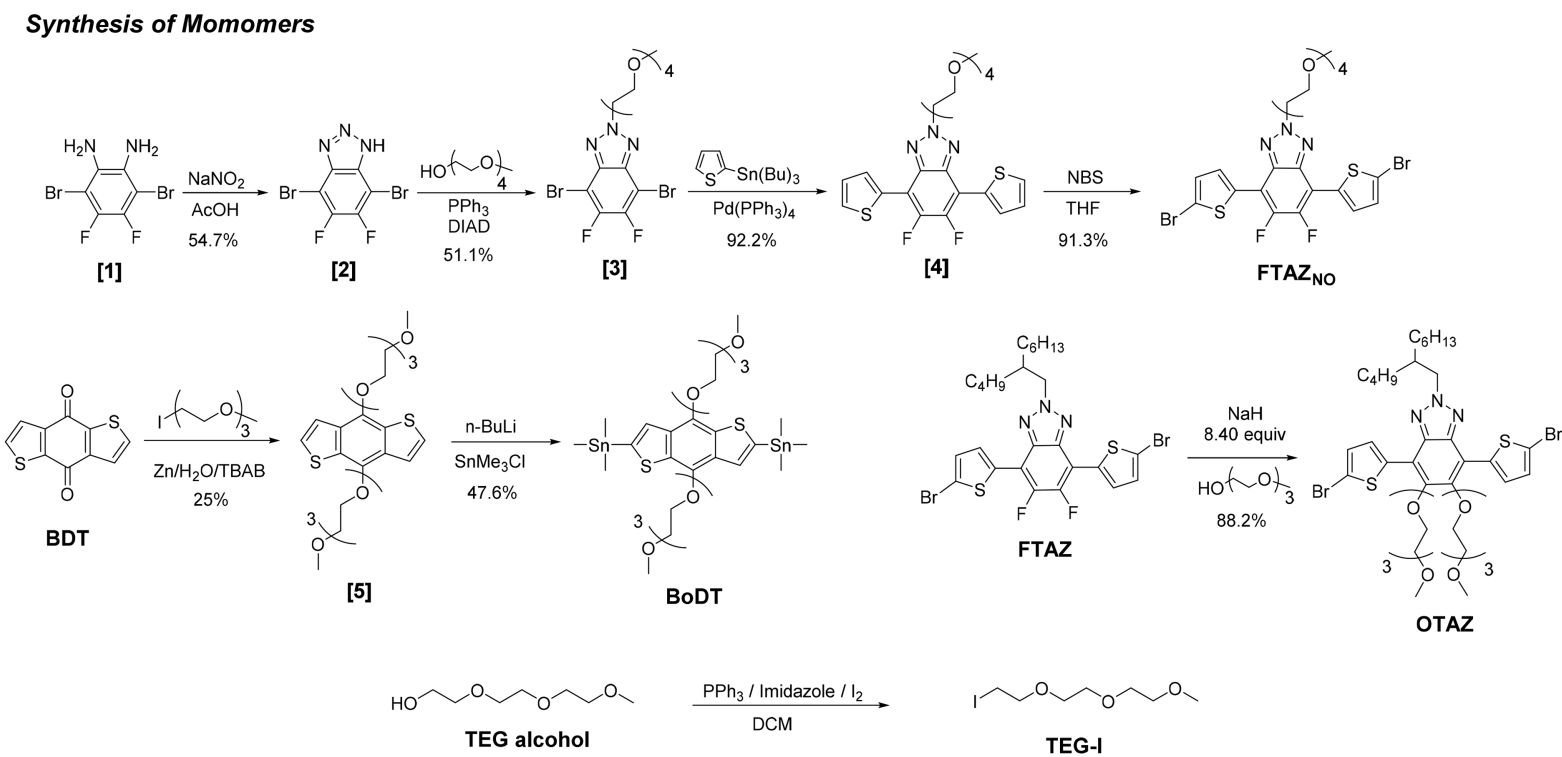

Synthesis of Polymers
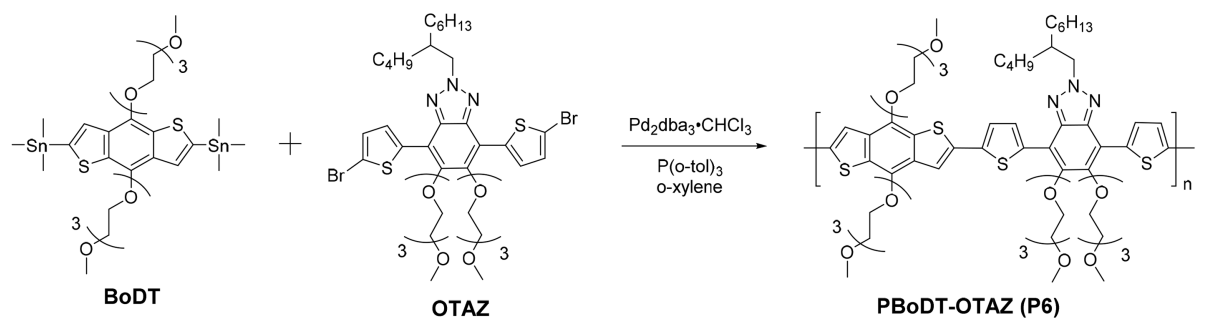

processed with toluene, to investigate the impact of side chains on device performance. Finally, with two polymers that have sufficient solubility in $2-\mathrm{MeTHF}^{15}$ a green solvent from renewable sources, we attempted to fabricate $\mathrm{BHJ}$ solar cells with IT-M and achieved decent device efficiencies ( 2\%).

\section{RESULTS AND DISCUSSION}

2.1. Design, Synthesis, and Basic Properties of PBnDT-FTAZ-Derived Polymers with OEG Side Chains. The original PBnDT-FTAZ structure has a total of five positions on the aromatic units which can be substituted with an OEG side chain: two alkyl chains on the benzodithiophene (BnDT), two fluorine and one more alkyl chain on the benzotriazole (TAZ). These positions have been labeled as $\mathrm{X}$, $\mathrm{Y}, \mathrm{Z}$ in Scheme 1. In this study, we applied linear OEG side chains to decorate these positions to render the solubility of the polymers in greener solvents. Scheme 1 exhibits the structures of all six conjugated polymers in this study: PBnDTFTAZ (P1), PBnDT-FTAZ ${ }_{\text {NO }}$ (P2), PBnDT-OTAZ (P3), PBoDT-FTAZ (P4), PBoDT-FTAZ ${ }_{\mathrm{NO}}$ (P5), and PBoDTOTAZ (P6). With the original PBnDT-FTAZ (P1) as the control, we introduce five new polymers (P2, P3, P4, P5, and P6) decorated with OEG side chains at varying positions.

Similar to the original PBnDT-FTAZ, the five OEG decorated polymers were synthesized via a conventional microwave-assisted Stille polycondensation polymerization of stannylated BnDT (and its analogs) monomers and brominated FTAZ (and its analogs) monomers. ${ }^{33-35}$ (Scheme 1).
The synthetic routes for those OEG-incorporated monomers $\left(\mathrm{FTAZ}_{\mathrm{NO}}, \mathrm{BoDT}\right.$, and OTAZ) are shown in Scheme 2. Specifically, compound $\mathbf{1}$ was prepared according to literature reports, ${ }^{36,37}$ which then underwent ring closure in the presence of sodium nitrate to afford compound 2 in a high yield of $90 \%{ }^{38}$ A Mitsunobu reaction between compound 2 and tetraethylene glycol monomethyl ether resulted in compound $3{ }^{39}$ Flanking thiophene was added via Stille coupling reaction to afford compound 4, which underwent bromination to obtain monomer FTAZ $\mathrm{NO}_{\mathrm{NO}}$ with one OEG chain on the nitrogen of the triazole ring. Another monomer, OTAZ, which contains two OEG side chains on the benzene ring of TAZ, was synthesized via a nucleophilic aromatic substitution of the OEG side chain onto the original FTAZ monomer. ${ }^{40}$ On the other hand, the OEG substituted benzodithiophene, BoDT, was synthesized via classical approaches. ${ }^{41}$ Synthetic details and corresponding characterization are included in the Supporting Information.

We utilized standard microwave-assisted Stille polycondensation conditions ${ }^{42,43}$ to synthesize all six polymers with high yields (>93\%). After precipitation in methanol, all polymers were purified by Soxhlet extraction with organic solvents: methanol, ethyl acetate, hexanes, and then chloroform. The molecular weight data of these polymers were measured by gel permeation chromatography (GPC) using both chloroform as the eluent at $35^{\circ} \mathrm{C}$ as well as trichlorobenezene as the eluent at $135{ }^{\circ} \mathrm{C}$ (details in Table S1 and Figure S16). Thermogravimetric analysis (TGA) indicates that polymers P3-P6 are less thermally stable than $\mathrm{P} 1$ and $\mathrm{P} 2$, with thermal degradation 
temperatures $\left(T_{\mathrm{d}}\right)$ of the former four polymers significantly lower than those of the latter two (Figure S14). We suspect the OEG chains directly linked with the aromatic units via oxygen (as appeared in the structures of P3-P6) would be thermally cleaved at lower temperature compared to the alkyl side chains, thus causing the lower thermal stability. Although P3-P6 have lower thermal stability than P1 and P2, it is important to note that all six materials made in this study are stable up to over $300{ }^{\circ} \mathrm{C}$, which is significantly higher than the possible high temperature $\left(\sim 150{ }^{\circ} \mathrm{C}\right)$ experienced for processing organic solar cells. We also attempted differential scanning calorimetry (DSC) to investigate the thermodynamic behaviors of these six polymers; however, no obvious glass transition temperature $\left(T_{\mathrm{g}}\right)$ could be obtained with these polymers in the temperature range $50-300{ }^{\circ} \mathrm{C}$. Table 1 summarizes the molecular weight and the thermal properties of these polymers, with experimental details in the Supporting Information.

Table 1. Molecular Weight Data and Thermal Properties of Polymers P1-P6

$\begin{array}{lcccccc} & \text { P1 } & \text { P2 } & \text { P3 } & \text { P4 } & \text { P5 } & \text { P6 } \\ M_{\mathrm{n}}{ }^{a}\left(\times 10^{3}\right) & 54.1 & 120.7 & 66.8 & 46.9 & 39.3 & 23.3 \\ \bigoplus^{a} & 7.2^{a} & 3.4 & 2.9 & 3.5 & 2.6 & 2.1 \\ T_{\mathrm{d}}{ }^{b}\left({ }^{\circ} \mathrm{C}\right) & 420 & 406 & 339 & 327 & 336 & 332\end{array}$

${ }^{a}$ Data were obtained with GPC using chloroform as the eluent at 35 ${ }^{\circ} \mathrm{C} . M_{\mathrm{n}}$ is the number average molecular weight, which has no unit (according to IUPAC). Due to the limited solubility of P1 in chloroform, it had significant aggregation which resulted in the broad dispersity $(\nexists)$. When run under high temperature $\left(135^{\circ} \mathrm{C}\right)$ and good solvent (trichlorobenzene), more accurate molecular weight was obtained (see Table S1 for more information). ${ }^{b}$ The temperature at $5 \%$ weight loss under nitrogen.

2.3. Optical, Electrochemical, and Solubility Properties. For easy comparison, we arbitrarily group these polymers based on the position and number of OEG side chains on either donor moiety (i.e., benzodithiophene unit) or acceptor moiety (i.e., dithienyl-benzotriazole unit, or dithienyl-TAZ). In each group, we compare the optical, electrochemical and solubility properties, in particular, focusing on the impact of OEG side chains. We first tested solubility of all polymers in a variety of solvents at room temperature, with the data summarized in Table 2. For solubility, we defined three categories: (1) soluble (>10 mg/mL); (2) slightly soluble (>1 $\mathrm{mg} / \mathrm{mL}$ but $<10 \mathrm{mg} / \mathrm{mL})$, and (3) insoluble $(<1 \mathrm{mg} / \mathrm{mL})$.

Group A: Alkyl Chain on BnDT with OEG Chains on TAZ. Group A contains the three polymers which retain the original structure of alkylated BnDT unit, and thus each have varying side chains on TAZ moiety. Specifically, P1 has a branched alkyl chain on the triazole ring, whereas P2 has a linear OEG side chain on the triazole ring. P3, on the other hand, retains the branched alkyl chain on the triazole ring, but has two linear OEG side chains replacing the original two fluorine substituents. Each of these structures can be found in Figure 1 a.

When looking at the solubility impact, replacing one branched alkyl chain with a linear OEG chain does not have a significant impact on the solubility of the polymer (e.g., comparing P1 with P2 in Table 2). However, having two OEG chains on the benzotriazole unit (e.g., P3) offers better solubility in greener solvents such as 2-MeTHF and ethyl acetate. Solubility in 2-MeTHF and ethyl acetate is notable, since it means that P3 should be processable with a nonhalogenated, nonaromatic solvent, which is a significant improvement from the aromatic toluene which has been seen more frequently in literature. Furthermore, 2-MeTHF is produced from renewable feedstock, thus making it ecologically friendly. Although this is an improvement in terms of processing conjugated polymers in a green solvent, P3 still lacks the solubility in simple alcohols (such as ethanol and methanol) as well as water, which are the target solvents for a truly green solvent based processing.

The absorption spectra of P2 both in solution and as thin film are very similar to those of P1 (Figure 1a), indicating that switching a branched alkyl chain to a linear OEG chain on the triazole ring of the TAZ unit does not have a strong impact on the absorption of the polymer. This can be explained by the fact that the oxygen substituent (in the OEG chain) is

Table 2. Solubilities of Polymers P1-P6 at Room Temperature ${ }^{a}$

\begin{tabular}{|c|c|c|c|c|c|c|c|c|c|}
\hline No. & Polymer & CB & CF & Toluene & $\begin{array}{l}\text { 2-Me } \\
\text { THF }\end{array}$ & EtOAc & Acetone & NMP & МeOH \\
\hline P1 & $\begin{array}{c}\text { PBnDT- } \\
\text { FTAZ }\end{array}$ & ++ & ++ & ++ & +- & -- & -- & -- & -- \\
\hline $\mathbf{P 2}$ & $\begin{array}{l}\text { PBnDT- } \\
\text { FTAZ }_{\text {NO }}\end{array}$ & ++ & ++ & ++ & +- & -- & -- & -- & -- \\
\hline P3 & $\begin{array}{c}\text { PBnDT- } \\
\text { OTAZ }\end{array}$ & ++ & ++ & ++ & ++ & +- & -- & -- & -- \\
\hline P4 & $\begin{array}{c}\text { PBoDT- } \\
\text { FTAZ }\end{array}$ & ++ & ++ & +- & +- & -- & -- & -- & -- \\
\hline P5 & $\begin{array}{l}\text { PBoDT- } \\
\text { FTAZ }_{\text {NO }}\end{array}$ & -- & ++ & -- & -- & -- & -- & -- & -- \\
\hline P6 & $\begin{array}{l}\text { PBoDT- } \\
\text { OTAZ }\end{array}$ & ++ & ++ & ++ & ++ & +- & +- & +- & +- \\
\hline
\end{tabular}

${ }^{a}[++]$ indicates soluble $(>10 \mathrm{mg} / \mathrm{mL}) .[+-]$ indicates slightly soluble $(>1 \mathrm{mg} / \mathrm{mL}$ but $<10 \mathrm{mg} / \mathrm{mL}) .[--]$ indicates insoluble $(<1 \mathrm{mg} / \mathrm{mL})$. 


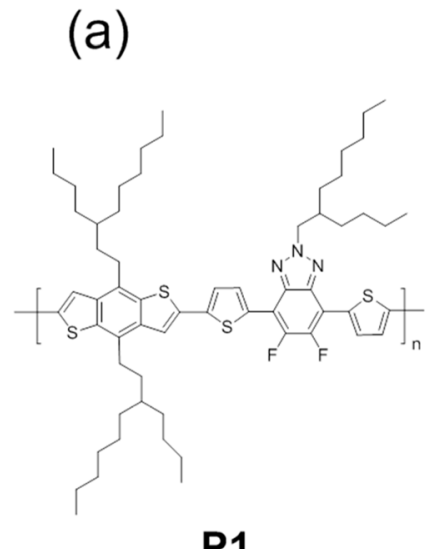

P1

(b)

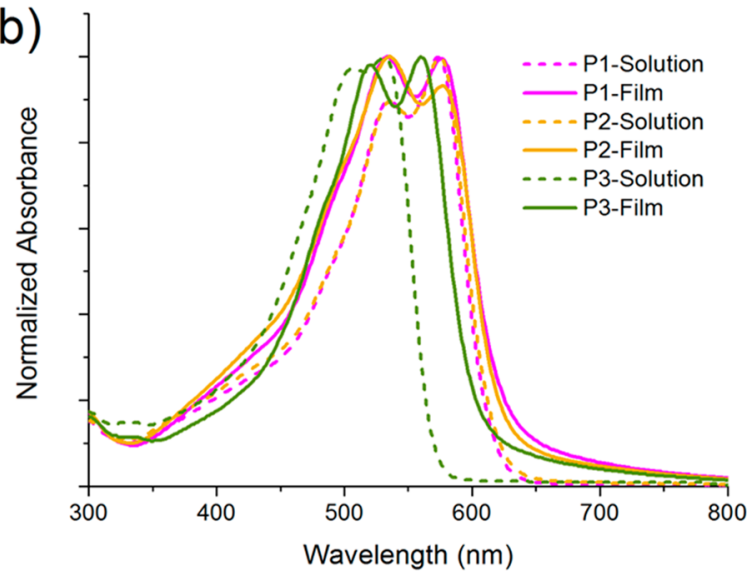

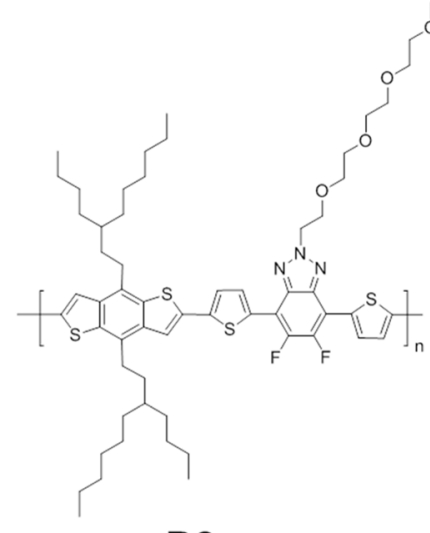

P2

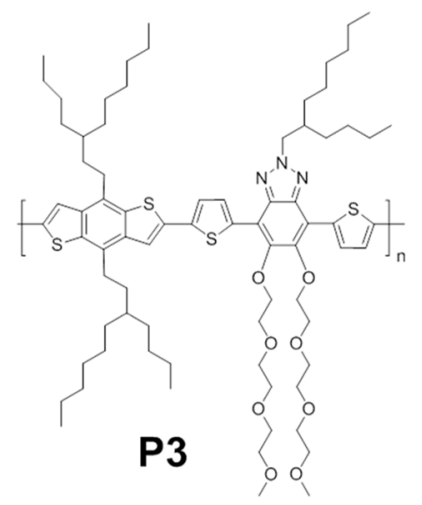

(C)

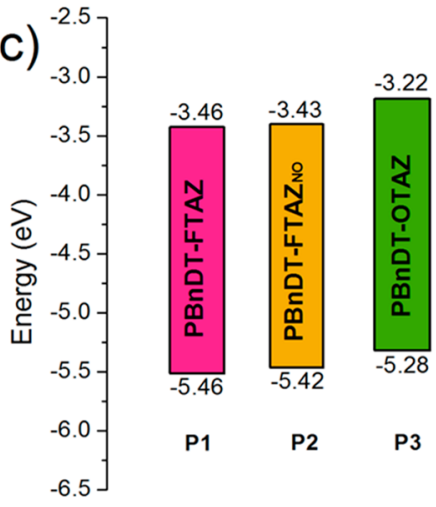

Figure 1. (a) Chemical structures for PBnDT-FTAZ (P1), PBnDT-FTAZ ${ }_{\mathrm{NO}}(\mathrm{P} 2)$, and PBnDT-OTAZ (P3), (b) normalized absorption in chloroform solutions (dashed lines) and as thin films (solid lines), and (c) energy levels determined by CV.

Table 3. Optical and Electrochemical Properties of Polymers P1-P3

\begin{tabular}{|c|c|c|c|c|c|c|c|c|c|}
\hline \multirow[b]{2}{*}{ no. } & \multirow[b]{2}{*}{ polymer } & \multicolumn{2}{|c|}{$\lambda_{\max }(\mathrm{nm})$} & \multirow[b]{2}{*}{$\lambda_{\text {onset }}(\mathrm{nm})$} & \multirow[b]{2}{*}{$E \mathrm{~g}_{\mathrm{Opt}}(\mathrm{eV})$} & \multirow[b]{2}{*}{$E_{\text {Номо }}(\mathrm{eV})$} & \multirow[b]{2}{*}{$E_{\text {LUMO }}(\mathrm{eV})$} & \multirow[b]{2}{*}{$\mathrm{E} \mathrm{g}_{\mathrm{Ele}}(\mathrm{eV})$} & \multirow[b]{2}{*}{$E \mathrm{LUMO}_{\text {Opt }}(\mathrm{eV}$} \\
\hline & & solution & film & & & & & & \\
\hline P1 & PBnDT-FTAZ & 535,573 & 534,576 & 623 & 2.00 & -5.46 & -2.76 & 2.70 & -3.46 \\
\hline P2 & PBnDT-FTAZ & 536,575 & 536,577 & 623 & 2.00 & -5.42 & -2.94 & 2.48 & -3.43 \\
\hline P3 & PBnDT-OTAZ & 506,531 & 521,560 & 603 & 2.06 & -5.28 & -2.83 & 2.45 & -3.22 \\
\hline
\end{tabular}

separated from the triazole ring of TAZ by one ethylene unit, thereby suppressing the electronic impact of the oxygen substituent on the original conjugated backbone (as in P1). However, substituting the fluorine substituents on the benzene ring of TAZ with OEG side chains has a significant impact on the absorption as the oxygen atoms are now directly linked with the TAZ unit. Compared with P1, the maximum absorption peaks of P3 are blue-shifted by 42 and $17 \mathrm{~nm}$ in solution and as thin film, respectively. The calculated band gap of $\mathrm{P} 3$, from the onset absorption in thin film, is slightly larger than that of P1 (2.06 eV vs $1.99 \mathrm{eV}$, Table 3). We identified two reasons to account for the significant different optical behavior of P3, in particular, in its solution. First, replacing the electron withdrawing fluorine substituents with electron donating oxygen substituents (as in OEG) would decrease the electron withdrawing nature of the TAZ unit and thereby weaken "donor-acceptor" nature of the conjugated backbone, leading to an enlarged band gap in the case of P3. This is the primary, and "intrinsic" reason. Second, replacing fluorine with oxygen would also diminish the noncovalent interactions induced by $F$, such as $F \cdots H, F \cdots S$, and $F \cdots \pi{ }^{44}$ these interactions help increase the planarity of the conjugated backbone (and certain aggregation) even in the solution. For $\mathrm{P} 3$, the lack of those intra/inter chain interactions and the increased solubility induced by the two additional OEG side chains would decrease the aggregation of polymer backbone in solution, resulting an enlarged band gap. This is the secondary, and "extrinsic" reason. This reduced aggregation for P3 can be further verified with temperature dependent UV-vis measurements (Figure S13). Specifically, both P1 and P2 maintain the aggregation peak at higher temperatures, while the aggregation peak of P3 decreases and eventually merges with the intramolecular charge transfer band.

Estimating the energy levels of these polymers via cyclic voltammetry disclose further the impact of OEG side chains (Figure 1c). As expected, there is negligible difference in the energy levels of highly occupied molecular orbital (HOMO) between P1 and P2, yet the HOMO energy level of P3 is noticeably increased by over $0.1 \mathrm{eV}$ when compared with that of P1 (or P2). This further supports that directly linking 

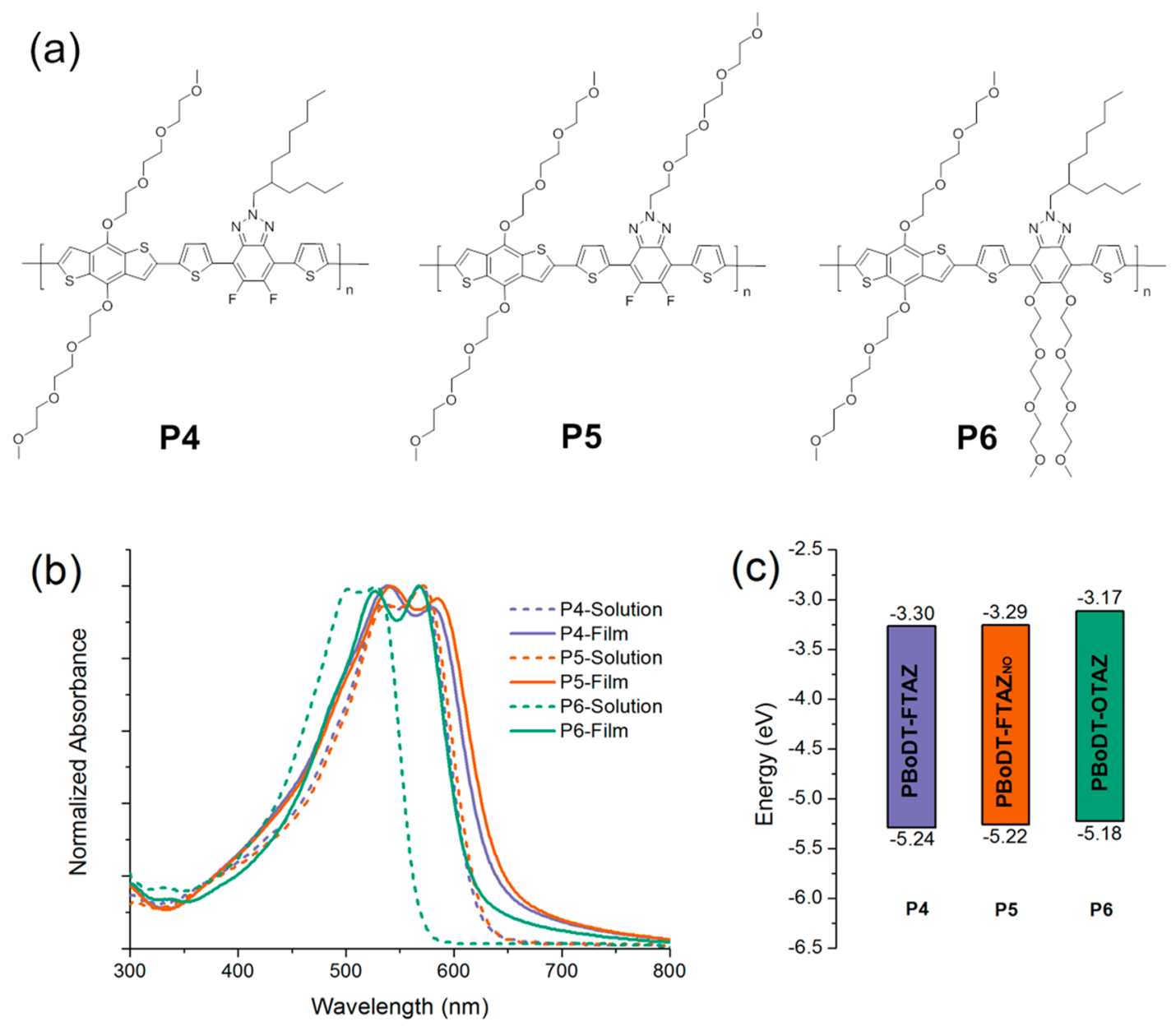

Figure 2. (a) Chemical structures for PBoDT-FTAZ (P4), PBoDT-FTAZ ${ }_{\mathrm{NO}}$ (P5), and PBoDT-OTAZ (P6), (b) normalized absorption in chloroform solutions (dashed lines) and as thin films (solid lines), and (c) energy levels determined by CV.

oxygen with TAZ would increase the overall electron density of the conjugated backbone and lead to an elevated HOMO.

Group B: OEG Side Chains on BoDT with Different Side Chains on TAZ. Group B also contains three polymers with slight structural variations, but this group replaced the branched alkylated BnDT unit in all the polymers of Group A with the OEG functionalized BoDT unit. Thus, from P4 to P6, the number and position of side chains on the TAZ unit vary, similar to the series of P1 to P3. On the other hand, it would also be interesting to compare P1 with P4 (or P2 vs P5 or P3 vs P6), since the only difference in here is the side chains on the benzodithiophene unit (i.e., alkyl vs OEG).

The loss of branched alkyl chains on the benzodithiophene unit, even replaced with linear OEG side chains, has a quite dramatic impact on the solubility of these three polymers (P4 to P6). This can be best illustrated by P5, where there is no branched side chain in presence, and this polymer shows the worst solubility behavior; it is only soluble in chloroform (Table 2). In contrast, P4 and P6 still have one branched alkyl chain on the triazole ring of the TAZ unit, which affords decent solubility of both polymers in toluene. We note that P6 has appreciable solubility in greener solvents (such as 2MeTHF, and even methanol), which can be ascribed to its four OEG chains (two on the benzodithiophene and two on the benzotriazole).

The trend in absorption behaviors of P4-P6 is quite similar to that observed in Group A (P1-P3). For example, both absorption features of P4 and P5 are quite similar in solution, and P6 shows a blue shift in its solution absorption (Figure $2 b$ ). This both highlights the impact of replacing fluorine with oxygen (in OEG chain) on the benzene ring of the TAZ unit and corroborated what we previously described in the case of P3. We further notice that replacing these two branched side chains on the benzodithiophene unit with two linear OEG side chains introduces a noticeable redshift in the thin film absorption of P5 when compared with P4; in contrast, there is not much redshift when comparing P1 with P2 in their thin film absorption spectra (Figure 2a). This is likely due to increased stacking of P5 in the solid state, since there is no more branched side chain on P5 (vs P2 that still has branched side chains on the benzodithiophene unit).

The more dramatic impact of replacing the alkyl side chains with OEG chains on the benzodithiophene unit was observed on the energy levels of these three polymers (P4-P6, Figure $2 \mathrm{c}$ ). Directly linking the OEG chains via the oxygen atoms to the benzodithiophene unit would significantly increase the electron density of the "donor" unit (i.e., benzodithiophene) in the conjugated backbone, thereby elevating the HOMO level of resulting polymers. Indeed, the HOMO energy levels of P4 and P5 are much elevated than those of P1 and P2, by $\sim 0.2$ $\mathrm{eV}$. With fluorine substituents were also replaced by oxygen (in OEG), P6 shows a similar HOMO energy level to those of P4 and P5. It appears that further increasing the electron density of the conjugated backbone by adding more electron rich 
Table 4. Basic Optical and Electrochemical Properties of Polymers P4-P6

\begin{tabular}{|c|c|c|c|c|c|c|c|c|c|}
\hline \multirow[b]{2}{*}{ no. } & \multirow[b]{2}{*}{ polymer } & \multicolumn{2}{|c|}{$\lambda_{\max }(\mathrm{nm})$} & \multirow[b]{2}{*}{$\lambda_{\text {onset }}(\mathrm{nm})$} & \multirow[b]{2}{*}{$E \mathrm{~g}_{\mathrm{Opt}}(\mathrm{eV})$} & \multirow[b]{2}{*}{$E_{\text {номо }}(\mathrm{eV})$} & \multirow[b]{2}{*}{$E_{\text {LUMO }}(\mathrm{eV})$} & \multirow[b]{2}{*}{$E \mathrm{~g}_{\mathrm{Ele}}(\mathrm{eV})$} & \multirow[b]{2}{*}{$E \mathrm{LUMO}_{\mathrm{Opt}}(\mathrm{eV})$} \\
\hline & & solution & film & & & & & & \\
\hline P4 & PBoDT-FTAZ & 535,570 & 539,580 & 640 & 1.94 & -5.24 & -3.05 & 2.19 & -3.30 \\
\hline P5 & PBoDT-FTAZ ${ }_{\mathrm{NO}}$ & 535,569 & 542,585 & 646 & 1.92 & -5.22 & -3.00 & 2.22 & -3.29 \\
\hline P6 & PBoDT-OTAZ & 504,528 & 527,568 & 618 & 2.01 & -5.18 & -2.87 & 2.31 & -3.17 \\
\hline
\end{tabular}
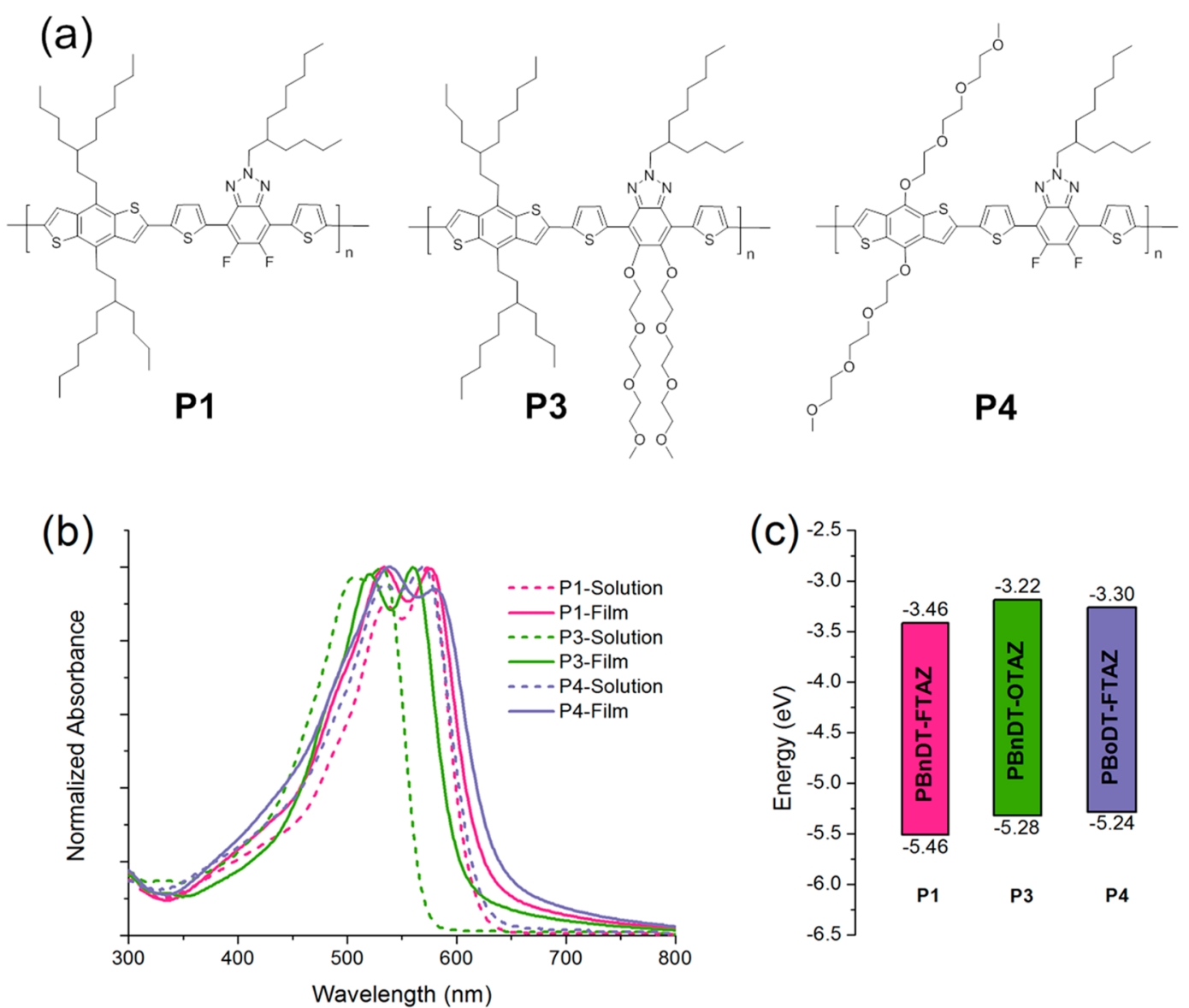

Figure 3. (a) Chemical structures for PBnDT-FTAZ (P1), PBnDT-OTAZ (P3), and PBoDT-FTAZ (P4), (b) normalized absorption in chloroform solutions (dashed lines) and as thin films (solid lines), and (c) energy levels determined by CV.

Table 5. Basic Optical and Electrochemical Properties of Polymers P1, P3, and P4

\begin{tabular}{|c|c|c|c|c|c|c|c|c|c|}
\hline \multirow[b]{2}{*}{ no. } & \multirow[b]{2}{*}{ polymer } & \multicolumn{2}{|c|}{$\lambda_{\max }(\mathrm{nm})$} & \multirow[b]{2}{*}{$\lambda_{\text {onset }}(\mathrm{nm})$} & \multirow[b]{2}{*}{$E \mathrm{~g}_{\text {Opt }}(\mathrm{eV})$} & \multirow[b]{2}{*}{$E_{\text {Номо }}(\mathrm{eV})$} & \multirow[b]{2}{*}{$E_{\text {LUMO }}(\mathrm{eV})$} & \multirow[b]{2}{*}{$E \mathrm{~g}_{\mathrm{Ele}}(\mathrm{eV})$} & \multirow[b]{2}{*}{$E \mathrm{LUMO}_{\text {Opt }}(\mathrm{eV}$} \\
\hline & & solution & film & & & & & & \\
\hline P1 & PBnDT-FTAZ & 535,573 & 534,576 & 623 & 1.99 & -5.46 & -2.76 & 2.70 & -3.46 \\
\hline P3 & PBnDT-OTAZ & 506,531 & 521,560 & 603 & 2.06 & -5.28 & -2.83 & 2.45 & -3.22 \\
\hline P4 & PBoDT-FTAZ & 538,572 & 539,580 & 640 & 1.94 & -5.24 & -3.05 & 2.19 & -3.30 \\
\hline
\end{tabular}

substituents (oxygen in OEG) does not seem to add much additional impact (in the case of P6). Table 4 summarizes all optical and electrochemical data for three polymers in Group B.

Group C: Donor or Acceptor with Two OEGs. In Group C, we deliberately picked P3 and P4 to compare with P1. P3 and P4 both contain two OEG side chains, yet in different positions of the conjugated backbone. With this group, we intend to understand the positional impact of these OEG side chains (since we keep the number of OEG chains constant).

Having three branched side chains on P3 (and two additional OEG side chains) offers noticeably better solubility than P4, which has only one branched side chains (Table 2).
Yet, the better stacking of P4 in the solid state leads to a reduced band gap when compared with P3 (Figure 3c). On the other hand, these two OEG side chains, regardless of where they are positioned (i.e., on the benzodithiophene unit or the benzene ring of the TAZ unit), are able to elevate the HOMO level of these two polymers (P3 and P4), interestingly, to a similar amount when compared with P1 (Figure $3 \mathrm{~b}$ ). Please note that the difference between the $\mathrm{P} 3$ and $\mathrm{P} 4$ are not just the position of these two OEG side chains. While P4 still has the two electron-withdrawing fluorine substituents on the benzene unit of the benzotriazole (with OEG chains on benzodithiophene), for P3, the two fluorine substituents are replaced with two OEG chain (with the oxygen substituents directly linked 
Table 6. Photovoltaic Characteristics for P2, P3, and P6 based BHJ Devices with IT-M as the Acceptor

\begin{tabular}{|c|c|c|c|c|c|}
\hline processing solvent & active layer $^{a}$ (1:1 ratio) & $J_{\mathrm{sc}}\left(\mathrm{mA} / \mathrm{cm}^{2}\right)$ & $V_{\mathrm{oc}}(\mathrm{V})$ & $F F(\%)$ & efficiency (\%) \\
\hline \multirow[t]{3}{*}{ toluene } & P2:IT-M & $15.44 \pm 0.71$ & $0.870 \pm 0.008$ & $52.5 \pm 2.3$ & $7.06 \pm 0.65$ \\
\hline & P3:IT-M & $11.58 \pm 0.55$ & $0.709 \pm 0.011$ & $43.4 \pm 0.9$ & $3.57 \pm 0.27$ \\
\hline & P6:IT-M & $9.51 \pm 0.32$ & $0.382 \pm 0.065$ & $33.6 \pm 2.0$ & $1.23 \pm 0.25$ \\
\hline \multirow[t]{2}{*}{ 2-MeTHF } & P3:IT-M & $7.58 \pm 0.36$ & $0.645 \pm 0.005$ & $42.9 \pm 1.0$ & $2.10 \pm 0.14$ \\
\hline & P6:IT-M & $5.36 \pm 0.25$ & $0.506 \pm 0.011$ & $37.6 \pm 0.4$ & $1.02 \pm 0.06$ \\
\hline
\end{tabular}

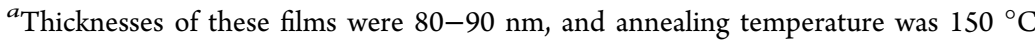

a)

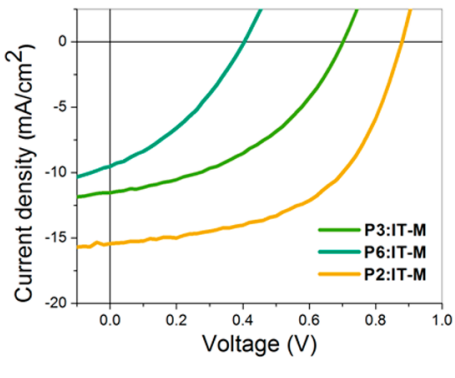

b)

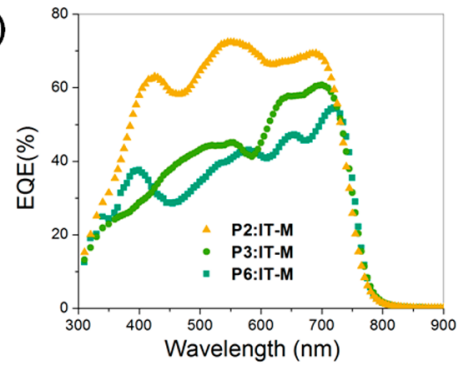

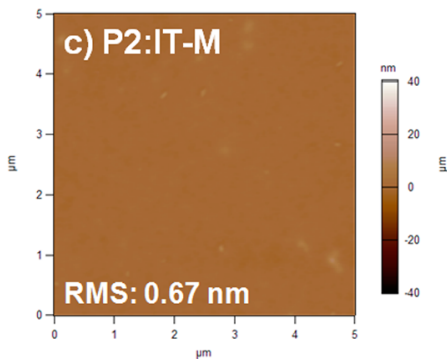
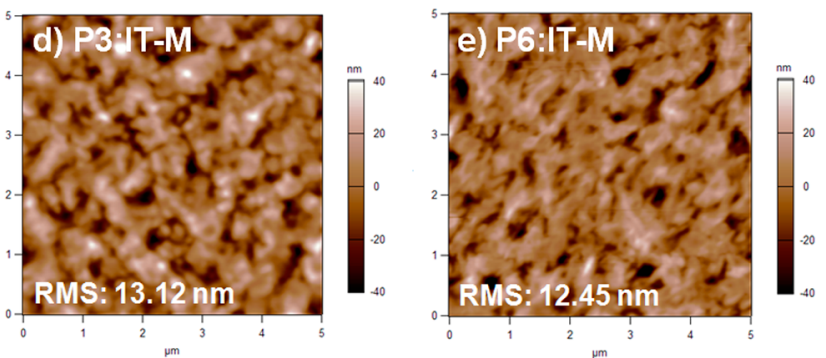

Figure 4. (a) $J-V$ curves and (b) EQE curves of devices of P2-, P3-, and P6 -based BHJ with IT-M as the acceptor, processed with toluene. (c-e) AFM images of films casted from toluene after thermal annealing at $150{ }^{\circ} \mathrm{C}$ for $10 \mathrm{~min}$.

with the benzene unit in TAZ). Thus, the 'rather similar HOMO energy levels' of P3 and P4 are the combined effect of fluorination and e-donating of OEG chains. Compared with P4, P3 seems to be a better choice of materials for OPVs processed with greener solvents. Table 5 summarizes the data for P1, P3, and P4 for convenience.

2.4. Device Results with Selected Polymers. As the ultimate goal of this study is to create green-solvent processed OPVs, we first explored toluene as the processing solvent for preparing the $\mathrm{BHJ}$ active layer, since toluene has shown success as a nonhalogenated processing solvent. We paired the polymers with IT-M, a nonfullerene acceptor (NFA), because previous work has achieved over $12 \%$ efficiency with FTAZ:ITM, processed with toluene. ${ }^{9}$ Although P4 and P5 (Table 2) did not mix well with IT-M in toluene due to the poor solubility of the two polymers in toluene, P2, P3, and P6 had sufficient solubility in toluene to enable the fabrication of active layers. To test the efficiency of each, an inverted device configuration of ITO $/ \mathrm{ZnO} /$ polymer:IT-M $/ \mathrm{MoO}_{3} / \mathrm{Al}$ was used for all devices in this study. Preliminary device results are summarized in Table 6, with representative J-V curves plotted in Figure $4 \mathrm{a}$ and external quantum efficiency (EQE) data plotted in Figure $4 \mathrm{~b}$.

Among all three BHJ blends, P2:IT-M shows the highest efficiency, in particular, due to the highest short circuit current $\left(J_{\text {sc }}\right)$. EQE data disclose that P2 can utilize its absorbed photons (400 to $600 \mathrm{~nm}$ range) to generate current, as efficiently as IT-M in the $\mathrm{BHJ}$ blend (600 to $800 \mathrm{~nm}$ range). In contrast, the other two polymers (P3 and P6) cannot efficiently utilize the absorbed photons, manifested by the low EQE in the range of 400 to $600 \mathrm{~nm}$. In addition, the IT-M also generates less $J_{s c}$ in its absorption range (Figure $4 \mathrm{~b}$ ). Both factors, in particular the former, contribute to the lower $J_{\mathrm{sc}}$ values for P3:IT-M and P6:IT-M based devices.

For the other two key device characteristics, open circuit voltage $\left(V_{\text {oc }}\right)$ and fill factor $(\mathrm{FF})$, we also observe a similar downward trend from P2 to P6 (Table 6). It becomes clear that, the device performance becomes worse with more OEG side chains (i.e., one OEG in P2, two OEG in P3, and four OEG in P6). The decreasing $V_{\text {oc }}$ can be roughly explained by the electronic effect that the OEG side chains have on the HOMO energy level. As shown in Figure S15, the energy of the HOMO increases from P2 $(-5.42 \mathrm{eV})$ to P3 $(-5.28 \mathrm{eV})$ to $\mathrm{P} 6(-5.18 \mathrm{eV})$, which follows the same trend in the $V_{\text {oc. }}$. We note that while the $V_{\text {oc }}$ is roughly proportional to the energy difference between the HOMO of the polymer donor and LUMO of the acceptor, there are more complex variables, such as CT state and nongeminate recombination, which serve as the root cause for the $V_{\text {oc }}$ loss. The details are still being investigated and are beyond the scope of this work.

Finally, we tentatively ascribe the low performance of P3 and P6 based devices, in particular, the significantly lower $J_{\text {sc }}$ and FF value of P6 based devices, to the unoptimal morphology of the $\mathrm{BHJ}$ blend likely caused by the lower solubility of P6 in toluene. Preliminary investigation on the morphology of these $\mathrm{BHJ}$ blends with atomic force microscopy (AFM) supports this. While a rather smooth film was observed with P2:IT-M based $\mathrm{BHJ}$ (Figure 4c), the other two films are very rough on the surface (Figure 4d, e), with root-mean-square (RMS) 

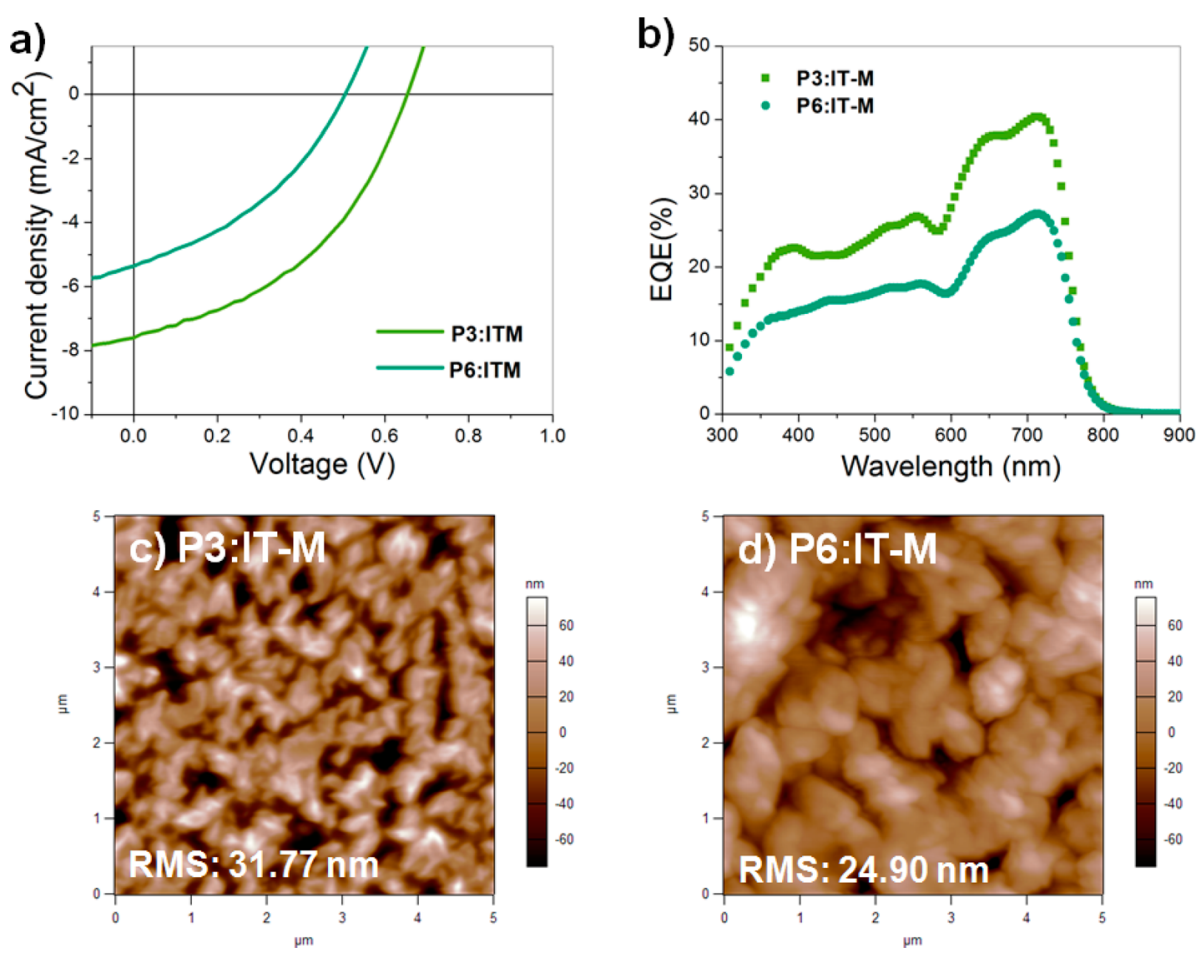

Figure 5. (a) $J-V$ curves and (b) EQE curves of devices of P3- and P6-based BHJ with IT-M as the acceptor, processed with 2-MeTHF. (c, d) AFM images of films casted from toluene after thermal annealing at $150{ }^{\circ} \mathrm{C}$ for $10 \mathrm{~min}$.

roughness close to 19 times larger than that of the P2:IT-M film.

Since the solubility data indicates that P3 and P6 are also quite soluble in 2-MeTHF (Table 2), we last tested this greener solvent (2-MeTHF) from renewable sources to process the active layer for solar cells. Collated in Table 6, the preliminary device performance is quite appreciable. An overall efficiency of over 2\% was obtained for P3:IT-M based $\mathrm{BHJ}$ devices (processed with 2-MeTHF), and over $1 \%$ was observed for P6:IT-M based ones. A careful look at the EQE spectra (Figure 5b) and surface morphology (Figure 5c, d) indicate that the morphology of these $\mathrm{BHJ}$ blends (processed with 2-MeTHF) is different from the ones processed with toluene. This significant change in morphology could lead to worse device performance. This apparent difference in morphology, for the same $\mathrm{BHJ}$ blend processed with different solvent (toluene vs 2 -MeTHF in here), is likely caused by the different interaction between the $\mathrm{BHJ}$ blend with the processing solvent. Because the kinetic process of solvent removal and $\mathrm{BHJ}$ formation is highly dependent on such interactions, different solvents can lead to dramatic difference in the morphology of the finished $\mathrm{BHJ}$ film. This has been commonly observed in $\mathrm{BHJ}$ solar cells. ${ }^{45}$ In addition, to further improve the device efficiency of such solar cells processed with green solvents, one should also consider other nonfullerene acceptors, such as N-2200. ${ }^{46}$

\section{CONCLUSION}

A few conclusions can be drawn from this work. First, to render a conjugated polymer soluble in green solvents, the idea of "the more OEG side chains, the better solubility," holds true. Furthermore, branched side chains are important to enhance the solubility; thus, the future design should consider the branched OEG side chains. ${ }^{22,23}$ Second, to minimize the impact of adopting OEG side chains on energy levels of the original conjugated polymer, one should avoid directly linking the OEG side chain to the aromatic units on the conjugated backbone via the oxygen atom (of the OEG chain). Third, adopting green solvents to process the $\mathrm{BHJ}$ blend poses significant challenges to the control of the morphology; the interaction between the $\mathrm{BHJ}$ blend with the processing (green) solvent needs to be seriously considered, given the BHJ film formation is a kinetic and dynamic process. These insights from this rather comprehensive and systematic study will offer help the future design of conjugated polymers to enable greensolvent processed OPV devices with high efficiency.

\section{ASSOCIATED CONTENT}

S Supporting Information

The Supporting Information is available free of charge on the ACS Publications website at DOI: 10.1021/acsapm.9b00044.

General methods and equipment; fabrication of OPV devices; detailed synthetic procedure for the monomers and corresponding polymers; NMR spectra and highresolution mass spectroscopy characterization; UV-vis spectra in solution, thin film, and temperature dependent; TGA curves; cyclic voltammograms and energy diagram; molecular weight information, details, and plot; optical and electrochemical properties of polymers (PDF)

\section{AUTHOR INFORMATION}

\section{Corresponding Authors}

*Email: chenzheng2013@jlu.edu.cn (Z.C.).

*Email: wyou@unc.edu (W.Y.).

ORCID $\odot$

Liang Yan: 0000-0003-4122-7466

Jeromy James Rech: 0000-0001-7963-9357

Qianqian Zhang: 0000-0002-8896-1708 
Wei You: 0000-0003-0354-1948

\section{Notes}

The authors declare no competing financial interest.

\section{ACKNOWLEDGMENTS}

Z.C. was financially supported by the Nature Science Foundation of China (51503075), International joint project of Science and technology department of Jilin province (20190701009GH), and the National Science Foundation (CBET-1639429). L.Y, J H. relieved support from the UNC Research Opportunities Initiative (ROI). J.J.R., Q.Z., and W.Y. are supported by the National Science Foundation (CBET1639429). This work was performed in part at the Chapel Hill Analytical and Nanofabrication Laboratory, CHANL, a member of the North Carolina Research Triangle Nanotechnology Network, RTNN, which is supported by the National Science Foundation (ECCS-1542015), as part of the National Nanotechnology Coordinated Infrastructure, NNCI. We sincerely appreciate the assistance on GPC by Ms. Jessica Bramhall of Professor Jason Locklin's lab in the College of Engineering at University of Georgia. The authors thank the University of North Carolina's Department of Chemistry Mass Spectrometry Core Laboratory, especially Brandie Ehrmann, for their assistance with mass spectrometry analysis.

\section{REFERENCES}

(1) Cheng, P.; Li, G.; Zhan, X.; Yang, Y. Next-Generation Organic Photovoltaics Based on Non-fFullerene Acceptors. Nat. Photonics 2018, 12, 131-142.

(2) Yan, C.; Barlow, S.; Wang, Z.; Yan, H.; Jen, A. K. Y.; Marder, S. R.; Zhan, X. Non-Fullerene Acceptors for Organic Solar Cells. Nat. Rev. Mater. 2018, 3, 18003.

(3) Zhang, G.; Zhao, J.; Chow, P. C. Y.; Jiang, K.; Zhang, J.; Zhu, Z.; Zhang, J.; Huang, F.; Yan, H. Nonfullerene Acceptor Molecules for Bulk Heterojunction Organic Solar Cells. Chem. Rev. 2018, 118, 3447-3507.

(4) Yuan, J.; Zhang, Y.; Zhou, L.; Zhang, G.; Yip, H.-L.; Lau, T.-K.; Lu, X.; Zhu, C.; Peng, H.; Johnson, P. A.; Leclerc, M.; Cao, Y.; Ulanski, J.; Li, Y.; Zou, Y. Single-Junction Organic Solar Cell with over 15\% Efficiency Using Fused-Ring Acceptor with ElectronDeficient Core. Joule 2019, DOI: 10.1016/j.joule.2019.01.004.

(5) Meng, L.; Zhang, Y.; Wan, X.; Li, C.; Zhang, X.; Wang, Y.; Ke, X.; Xiao, Z.; Ding, L.; Xia, R.; Yip, H. L.; Cao, Y.; Chen, Y. Organic and Solution-Processed Tandem Solar Cells with $17.3 \%$ Efficiency. Science 2018, 361, 1094-1098.

(6) Zhang, S. Q.; Ye, L.; Zhang, H.; Hou, J. H. Green-SolventProcessable organic solar cells. Mater. Today 2016, 19, 533-543.

(7) Capello, C.; Fischer, U.; Hungerbühler, K. What is a Green Solvent? A Comprehensive Framework for the Environmental Assessment of Solvents. Green Chem. 2007, 9, 927.

(8) Fan, Q.; Zhu, Q.; Xu, Z.; Su, W.; Chen, J.; Wu, J.; Guo, X.; Ma, W.; Zhang, M.; Li, Y. Chlorine substituted 2D-Conjugated Polymer for High-Performance Polymer Solar Cells with $13.1 \%$ Efficiency via Toluene Processing. Nano Energy 2018, 48, 413-420.

(9) Ye, L.; Xiong, Y.; Zhang, Q.; Li, S.; Wang, C.; Jiang, Z.; Hou, J.; You, W.; Ade, H. Surpassing 10\% Efficiency Benchmark for Nonfullerene Organic Solar Cells by Scalable Coating in Air from Single Nonhalogenated Solvent. Adv. Mater. 2018, 30, 1705485.

(10) Park, G. E.; Choi, S.; Park, S. Y.; Lee, D. H.; Cho, M. J.; Choi, D. H. Eco-Friendly Solvent-Processed Fullerene-Free Polymer Solar Cells with over 9.7\% Efficiency and Long-Term Performance Stability. Adv. Energy Mater. 2017, 7, 1700566.

(11) Zhao, W.; Ye, L.; Li, S.; Liu, X.; Zhang, S.; Zhang, Y.; Ghasemi, M.; He, C.; Ade, H.; Hou, J. Environmentally-Friendly Solvent Processed Fullerene-Free Organic Solar Cells Enabled by Screening Halogen-Free Solvent Additives. Sci. China Mater. 2017, 60, 697-706.
(12) Ye, L.; Xiong, Y.; Li, S.; Ghasemi, M.; Balar, N.; Turner, J.; Gadisa, A.; Hou, J.; O'Connor, B. T.; Ade, H. Precise Manipulation of Multilength Scale Morphology and Its Influence on Eco-Friendly Printed All-Polymer Solar Cells. Adv. Funct. Mater. 2017, 27, 1702016.

(13) Zhao, W.; Zhang, S.; Zhang, Y.; Li, S.; Liu, X.; He, C.; Zheng, Z.; Hou, J. Environmentally Friendly Solvent-Processed Organic Solar Cells that are Highly Efficient and Adaptable for the Blade-Coating Method. Adv. Mater. 2018, 30, 1704837.

(14) Qin, Y. P.; Ye, L.; Zhang, S. Q.; Zhu, J.; Yang, B.; Ade, H.; Hou, J. H. A Polymer Design Strategy Toward Green Solvent Processed Efficient Non-Fullerene Polymer Solar Cells. J. Mater. Chem. A 2018, 6, 4324-4330.

(15) Aycock, D. F. Solvent Applications of 2-Methyltetrahydrofuran in Organometallic and Biphasic Reactions. Org. Process Res. Dev. 2007, $11,156-159$.

(16) Chen, X.; Liu, X.; Burgers, M. A.; Huang, Y.; Bazan, G. C. Green-Solvent-Processed Molecular Solar Cells. Angew. Chem., Int. Ed. 2014, 53, 14378-14381.

(17) Fan, B.; Ying, L.; Wang, Z.; He, B.; Jiang, X.-F.; Huang, F.; Cao, Y. Optimisation of Processing Solvent and Molecular Weight for the Production of Green-Solvent-Processed All-Polymer Solar Cells with a Power Conversion Efficiency over 9\%. Energy Environ. Sci. 2017, 10, 1243-1251.

(18) Dayneko, S. V.; Hendsbee, A. D.; Welch, G. C. Combining Facile Synthetic Methods with Greener Processing for Efficient Polymer-Perylene Diimide Based Organic Solar Cells. Small Methods 2018, 2, 1800081.

(19) Liao, C.; Zhang, M.; Xu, X.; Liu, F.; Li, Y.; Peng, Q. Green Solvent-Processed Efficient Non-Fullerene Organic Solar Cells Enabled by Low-Bandgap Copolymer Donors with EDOT Side Chains. J. Mater. Chem. A 2019, 7, 716.

(20) Fan, B.; Zhu, P.; Xin, J.; Li, N.; Ying, L.; Zhong, W.; Li, Z.; Ma, W.; Huang, F.; Cao, Y. High-Performance Thick-Film All-Polymer Solar Cells Created Via Ternary Blending of a Novel Wide-Bandgap Electron-Donating Copolymer. Adv. Energy Mater. 2018, 8, 1703085.

(21) Chen, Y.; Zhang, S.; Wu, Y.; Hou, J. Molecular Design and Morphology Control Towards Efficient Polymer Solar Cells Processed Using Non-Aromatic and Non-Chlorinated Solvents. Adv. Mater. 2014, 26, 2744-2749.

(22) Nguyen, T. L.; Lee, C.; Kim, H.; Kim, Y.; Lee, W.; Oh, J. H.; Kim, B. J.; Woo, H. Y. Ethanol-Processable, Highly Crystalline Conjugated Polymers for Eco-Friendly Fabrication of Organic Transistors and Solar Cells. Macromolecules 2017, 50, 4415-4424.

(23) Kim, Y.; Choi, J.; Lee, C.; Kim, Y.; Kim, C.; Nguyen, T. L.; Gautam, B.; Gundogdu, K.; Woo, H. Y.; Kim, B. J. Aqueous Soluble Fullerene Acceptors for Efficient Eco-Friendly Polymer Solar Cells Processed from Benign Ethanol/Water Mixtures. Chem. Mater. 2018, $30,5663-5672$.

(24) Chen, Y.; Cui, Y.; Zhang, S.; Hou, J. Molecular Design Toward Efficient Polymer Solar Cells Processed by Green Solvents. Polym. Chem. 2015, 6, 4089-4095.

(25) Duan, C.; Zhang, K.; Zhong, C.; Huang, F.; Cao, Y. Recent Advances in Water/Alcohol-Soluble Pi-Conjugated Materials: New Materials and Growing Applications in Solar Cells. Chem. Soc. Rev. 2013, 42, 9071-9104.

(26) Meng, B.; Song, H.; Chen, X.; Xie, Z.; Liu, J.; Wang, L. Replacing Alkyl with Oligo(ethylene glycol) as Side Chains of Conjugated Polymers for Close $\pi-\pi$ Stacking. Macromolecules 2015, $48,4357-4363$.

(27) Chen, X.; Zhang, Z.; Ding, Z.; Liu, J.; Wang, L. Diketopyrrolopyrrole-based Conjugated Polymers Bearing Branched Oligo(Ethylene Glycol) Side Chains for Photovoltaic Devices. Angew. Chem., Int. Ed. 2016, 55, 10376-10380.

(28) Brebels, J.; Manca, J. V.; Lutsen, L.; Vanderzande, D.; Maes, W. High Dielectric Constant Conjugated Materials for Organic Photovoltaics. J. Mater. Chem. A 2017, 5, 24037-24050.

(29) Chen, X. X.; Zhang, Z. J.; Liu, J.; Wang, L. X. A Polymer Electron Donor Based on Isoindigo Units Bearing Branched 
Oligo(ethylene glycol) Side Chains for Polymer Solar Cells. Polym. Chem. 2017, 8, 5496-5503.

(30) Brebels, J.; Douvogianni, E.; Devisscher, D.; Thiruvallur Eachambadi, R.; Manca, J.; Lutsen, L.; Vanderzande, D.; Hummelen, J. C.; Maes, W. An Effective Strategy to Enhance the Dielectric Constant of Organic Semiconductors - CPDTTPD-Based Low Bandgap Polymers Bearing Oligo(ethylene glycol) Side Chains. J. Mater. Chem. C 2018, 6, 500-511.

(31) Liu, X.; Xie, B. M.; Duan, C. H.; Wang, Z. J.; Fan, B. B.; Zhang, K.; Lin, B. J.; Colberts, F. J. M.; Ma, W.; Janssen, R. A. J.; Huang, F.; Cao, Y. A High Dielectric Constant Non-Fullerene Acceptor for Efficient Bulk-Heterojunction Organic Solar Cells. J. Mater. Chem. A 2018, 6, 395-403.

(32) Lee, C.; Lee, H. R.; Choi, J.; Kim, Y.; Nguyen, T. L.; Lee, W.; Gautam, B.; Liu, X.; Zhang, K.; Huang, F.; Oh, J. H.; Woo, H. Y.; Kim, B. J. Efficient and Air-Stable Aqueous-Processed Organic Solar Cells and Transistors: Impact of Water Addition on Processability and Thin-Film Morphologies of Electroactive Materials. Adv. Energy Mater. 2018, 8, 1802674.

(33) Price, S. C.; Stuart, A. C.; Yang, L.; Zhou, H.; You, W. Fluorine Substituted Conjugated Polymer of Medium Band Gap Yields 7\% Efficiency in Polymer-Fullerene Solar Cells. J. Am. Chem. Soc. 2011, 133, 4625-4631.

(34) Zhou, H.; Yang, L.; Stuart, A. C.; Price, S. C.; Liu, S.; You, W. Development of Fluorinated Benzothiadiazole as a Structural Unit for a Polymer Solar Cell of 7\% Efficiency. Angew. Chem., Int. Ed. 2011, 50, 2995-2998.

(35) Li, W.; Albrecht, S.; Yang, L.; Roland, S.; Tumbleston, J. R.; McAfee, T.; Yan, L.; Kelly, M. A.; Ade, H.; Neher, D.; You, W. Mobility-Controlled Performance of Thick Solar Cells Based on Fluorinated Copolymers. J. Am. Chem. Soc. 2014, 136, 15566-15576.

(36) Dutta, G. K.; Kim, T.; Choi, H.; Lee, J.; Kim, D. S.; Kim, J. Y.; Yang, C. Synthesis of Fluorinated Analogues of a Practical Polymer TQ for Improved Open-Circuit Voltages in Polymer Solar Cells. Polym. Chem. 2014, 5, 2540-2547.

(37) Xu, S.; Feng, L.; Yuan, J.; Zhang, Z. G.; Li, Y.; Peng, H.; Zou, Y. Hexafluoroquinoxaline Based Polymer for Nonfullerene Solar Cells Reaching 9.4\% Efficiency. ACS Appl. Mater. Interfaces 2017, 9, $18816-18825$.

(38) Liu, X.; Cai, P.; Chen, Z.; Zhang, L.; Zhang, X.; Sun, J.; Wang, H.; Chen, J.; Peng, J.; Chen, H.; Cao, Y. D-A Copolymers Based on 5,6-Difluorobenzotriazole and Oligothiophenes: Synthesis, Field Effect Transistors, and Polymer Solar Cells. Polymer 2014, 55, $1707-1715$.

(39) Kim, J.-H.; Song, C. E.; Kang, I.-N.; Shin, W. S.; Zhang, Z.-G.; Li, Y.; Hwang, D.-H. Conventional and Inverted Photovoltaic Cells Fabricated Using New Conjugated Polymer Comprising Fluorinated Benzotriazole and Benzodithiophene Derivative. Bull. Korean Chem. Soc. 2014, 35, 1356-1364.

(40) Kim, G.-W.; Lee, J.; Kang, G.; Kim, T.; Park, T. DonorAcceptor Type Dopant-Free, Polymeric Hole Transport Material for Planar Perovskite Solar Cells (19.8\%). Adv. Energy Mater. 2018, 8, 1701935.

(41) Beimling, P.; Kossmehl, G. Synthesis of Benzo[1,2-B-4,5B']Dithiophene and Its 4,8-Dimethoxy and 4,8-Dimethyl Derivatives. Chem. Ber. 1986, 119, 3198-3203.

(42) Coffin, R. C.; Peet, J.; Rogers, J.; Bazan, G. C. Streamlined Microwave-Assisted Preparation of Narrow-Bandgap Conjugated Polymers for High-Performance Bulk Heterojunction Solar Cells. Nat. Chem. 2009, 1, 657-661.

(43) Li, W.; Yang, L.; Tumbleston, J. R.; Yan, L.; Ade, H.; You, W. Controlling Molecular Weight of a High Efficiency Donor-Acceptor Conjugated Polymer and Understanding Its Significant Impact on Photovoltaic Properties. Adv. Mater. 2014, 26, 4456-4462.

(44) Zhang, Q.; Kelly, M. A.; Bauer, N.; You, W. The Curious Case of Fluorination of Conjugated Polymers for Solar Cells. Acc. Chem. Res. 2017, 50, 2401-2409.
(45) Richter, L. J.; DeLongchamp, D. M.; Amassian, A. Morphology Development in Solution-Processed Functional Organic Blend Films: An In Situ Viewpoint. Chem. Rev. 2017, 117, 6332-6366.

(46) Zhou, L.; Lau, T.-K.; Peng, H.; Qiu, B.; Jiang, L.; Lu, X.; Zhang, G.; Yuan, J.; Li, Y.; Zou, Y. Realizing 8.6\% Efficiency from NonHalogenated Solvent Processed Additive Free All Polymer Solar Cells with a Quinoxaline Based Polymer. Solar RRL 2019, 1800340. 